\title{
A communication perspective on open strategy and open innovation
}

\author{
Leonhard Dobusch (D) - Waldemar Kremser • David Seidl · Felix Werle
}

Published online: 31 August 2017

(C) The Author(s) 2017. This article is an open access publication.

\begin{abstract}
This paper presents a systematic analysis of the similarities and differences between the fields of open innovation and open strategy. In particular, we examine the concept of openness from a communication-centered perspective and compare processes of open innovation and open strategy with regard to the openness they exhibit. By distinguishing between openness in terms of sociality, factuality and temporality, we find that cases of open strategy tend to exhibit lower degrees of openness in the social dimension and higher degrees in the other two when compared to open innovation. Notwithstanding variation within and between the fields of open innovation and open strategy, opening up in one dimension of communication will generally result in pressures to decrease openness with regards to the other dimensions - unless particular tools are employed that help cope with the additional degrees of communicative complexity.
\end{abstract}

\footnotetext{
L. Dobusch $(\bowtie)$

Department of Organization and Learning, University of Innsbruck, Universitätsstr. 15, 6020 Innsbruck, Austria

E-Mail: Leonhard.Dobusch@uibk.ac.at

W. Kremser

Institute for Management Research, Radboud University Nijmegen, 9108, 6500 HK Nijmegen, Netherlands

E-Mail: W.Kremser@fm.ru.nl

D. Seidl · F. Werle

Department of Business Administration, University of Zurich, Universitätsstrasse 84, 8006 Zürich, Switzerland

D. Seidl

E-Mail: David.Seidl@business.uzh.ch

F. Werle

E-Mail: Felix.Werle@institut-icm.de
} 
Keywords Open strategy · Open innovation · Communication theory

\section{Introduction}

Over the last few years radical new practices have emerged in strategy-making that have been described as "open strategy" (Whittington et al. 2011; Hautz et al. 2017). While strategy was conventionally understood as the exclusive domain of an elite group within an organization, and treated with utmost secrecy, we find that companies are increasingly opening up their strategy-making processes, propagating greater transparency and inclusion. New practices such as strategy crowdsourcing (Aten and Thomas 2016; Stieger et al. 2012), the interorganizational exploration of strategic issues (Werle and Seidl 2012), and strategy jamming (Palmisano 2004) are all indicative of this tendency. These new developments in the area of strategy have been associated with that of open innovation more than a decade ago (Chesbrough and Appleyard 2007; Doz and Kosonen 2008). This suggests that, despite some differences between these two domains, some of the insights that are gained in studies on open innovation might also pertain to open strategy. A transfer of knowledge between these two domains calls for a systematic analysis of the similarities and differences between these two fields. This is what we set out to do in this essay. In particular, we will examine the concept of openness in the fields of open innovation and open strategy and we will compare these two fields with regard to the openness they exhibit.

The first step in this endeavor is identifying a theoretical perspective that is general enough to capture both phenomena. The existing frameworks that studies on open innovation use seem unsuitable for our purpose, because they focus on aspects of innovation that are not necessarily present in the domain of strategy, such as the role of intellectual property rights (Chesbrough 2006; Henkel 2006; von Hippel and von Krogh 2003). Given that in the case of both innovation and strategy openness concerns aspects of communication, we suggest that the two domains could be fruitfully analyzed from a communication-centered perspective (Craig and Muller 2007; Putnam and Mumby 2013; Luhmann 1995). In each domain, openness can be conceptualized as the opening up of communication processes in terms of the different dimension of communication: opening up in terms of the range of different participants, in terms of the range of different topics allowed and in terms of the range of different purposes of the communication process.

Against this backdrop, we specify our research question as follows: how do communication processes in open strategy differ from those in open innovation. Our analysis reveals several similarities between the two domains in terms of some of its communication topics, participants and purposes. However, we also identify some marked differences in terms of the particular constellation of openness in the three dimensions. While open innovation tends to be more open in terms of range of participants, it tends to be less open in terms of range of topics and purposes. Open strategy in contrast tends to be less open in terms of the range of participants but more open in the other two dimensions. As we argue, this is partly the result of 
an attempt at keeping the overall complexity of the communication process within manageable limits.

The rest of this essay is structured into four sections. In the first section, we will draw on communication theory to develop our approach to examining openness in the context of open innovation and open strategy. This will result in a communicationtheoretical framework, on the basis of which we will discuss the commonalities and differences between open innovation and open strategy in the following section. In the fourth section we will discuss our findings and relate them to the existing literature. In the concluding section, we will rehearse the main points of our argument and develop an agenda for future research on openness in strategy and innovation.

\section{Characterization of open strategy and open innovation in the literature}

Comparing open innovation and open strategy requires that we start by defining clearly each concept. In the case of open innovation, a decade of research has led to a variety of approaches, most of which are juxtaposed to "traditional", "proprietary" or "closed" models of innovation. Chesbrough (2006, p. 1), for example, defines open innovation negatively as "the antithesis of the traditional vertical integration model where internal research and development (R\&D) activities lead to internally developed products that are then distributed by the firm". In contrast to the traditional approach, according to this newer perspective innovation processes "combine internal and external ideas into architectures and systems" (Chesbrough 2006, p. 1). Similarly, West and Gallagher, referring to the article by Cohen and Levinthal (1990) on absorptive capacity, define "open innovation as systematically encouraging and exploring a wide range of internal and external sources for innovation opportunities, consciously integrating that exploration with firm capabilities and resources, and broadly exploiting those opportunities through multiple channels" (West and Gallagher 2006, p. 320). In contrast to these very broad and paradigmatic approaches to open innovation, others focus more on the role of intellectual property (IP) in open innovation. Baldwin and von Hippel (2011, p. 1400), for example, state that an "innovation is 'open' in our terminology when all information related to the innovation is a public good - nonrivalrous and nonexcludable". This definition of "open" differs from Chesbrough's much broader notion of openness in the sense of 'openness' to the acquisition of new ideas, patents, products, etc., from outside [an organization's] boundaries" (Baldwin and von Hippel 2011, p. 1400).

Soon after Henry Chesbrough (2003a, 2003b) popularized the concept of "open innovation", he was accused of presenting "old wine in new bottles". In a paper with exactly this phrase in the title, Trott and Hartmann (2009) brought forward considerable evidence that many corporations have long been engaged in R\&D activities that resemble the principles of open innovation that Chesbrough (2003a) described and that in fact there was already some research on each principle. However, while certainly making some valid points, Trott and Hartmann (2009) overlooked Chesbrough's main contribution, which is the recombination and repackaging of different, previously unconnected insights into innovation under a new label: open innovation. 
Even Trott and Hartmann themselves acknowledge that "the dichotomy between closed innovation and open innovation may be true in theory" and call it a "helpful and stimulating tactic to introduce a "new concept" (such as Open Innovation) to companies that are already most of the way there" (Trott and Hartmann 2009, p. 728).

Some of the founding works of open innovation have also laid the foundation for the more recent debate on open strategy, which analogously distinguishes "open" from "traditional" or "closed" approaches to strategy-making. Tying the notion of open strategy to that of open innovation, Chesbrough and Appleyard argued that open strategy "balances the tenets of traditional business strategy with the promise of open innovation" (Chesbrough and Appleyard 2007, p. 58). Similarly, in their assessment of the concept of open strategy, Whittington et al. (2011) suggested that open strategy challenges traditionally exclusive approaches (see also Hautz et al. 2017). In their definition of open strategy, Whittington et al. (2011, p. 534) went so far as to argue that "open innovation is a subset of open strategy: innovation is just one of many kinds of strategy process increasingly subject to openness". Stieger et al. (2012), in one of the first empirical works on open strategy, similarly emphasized that the origins of employing crowdsourcing methods in strategy-making lie in open innovation. There is a host of different items that can be subsumed under the label of "open strategy", including the inter-organizational exploration of strategic topics (Werle and Seidl 2012), collaborative strategy-making between organizations (Hardy et al. 2006), strategy crowdsourcing (Stieger et al. 2012), strategy jamming (Palmisano 2004) and public strategy updates (Whittington et al. 2011).

While open innovation and open strategy have many aspects in common, the central link between the two is, of course, "openness". Also, in both open strategy and open innovation, previous studies identify substantially similar - albeit differently labeled - dimensions of openness when describing the respective processes. Dahlander and Gann, who conducted a systematic review of the literature on open innovation, distinguished different forms of openness with regard to inbound vs outbound processes and non-pecuniary vs pecuniary processes and discussed "two forms of inbound innovation - Acquiring and Sourcing; and two outbound - Selling and Revealing" (Dahlander and Gann 2010, p. 700). Similarly, in the context of crowd science projects, Franzoni and Sauermann distinguished between "openness in project participation and openness with respect to the disclosure of intermediate inputs such as data or problem solving approaches" (Franzoni and Sauermann 2014, p. 7). In the field of open strategy, Whittington et al. (2011, p. 535) defined openness as "widening inclusion and increasing transparency" with regard to both internal and external stakeholders.

While the distinction that Dahlander and Gann (2010) drew between pecuniary and non-pecuniary aspects specifically relates to open innovation inputs and outcomes in the form of products or intellectual property rights, their distinction between inbound and outbound innovation is similar to the core distinction that Whittington et al. (2011) drew between inclusion and transparency. The distinction between openness in participation and the disclosure of intermediate inputs that Franzoni and Sauermann (2014) proposed also refers to similar characteristics. 


\section{A communication perspective on openness}

In its most general sense, the notions of inclusion, participation, and transparency in the literature on open innovation and open strategy concern aspects of communication regarding innovation and strategy. Hence, a communication perspective can be a useful device for a comparative analysis of these streams of literature.

When focusing on communication, the most straightforward interpretation of openness refers us to the number of possibilities there are to carry a specific communication process forward in a meaningful way: If many different people can say many different things for many different reasons, we would consider this to be an open communication process. In a closed communication process, on the other hand, only a very small group of people can say very specific things for a very limited number of (legitimate) reasons - everything else will be considered meaningless for this communication process. Hence, when taking a communication perspective, the notion of openness directly refers us to the concept of meaning.

Building on Luhmann's conception of meaning (1995, 2012, 2013), the openness of any communication process can be further specified in terms of the three dimensions of meaning - sociality, factuality and temporality. In social systems, sociality "concerns what one at any time accepts [...] as an 'alter ego"" (Luhmann 1995, p. 80). The social dimension, therefore, refers us to the question of which individuals are treated as relevant participants in a communication process; i. e. who is addressed and/or will be listened to. Hence, the openness of a strategy or innovation process with regards to the social dimension can be operationalized in terms of the variety of the different groups of people whose contributions will be treated as meaningful for that process. While in a typical "closed" innovation process, for example, only a small R\&D team will be allowed to participate, open processes are often set up in such a way that they allow a wide variety of internal and external stakeholders to take part (e. g., Chesbrough 2006).

Factuality or the fact dimension of meaning, in turn, concerns the "themes of meaningful communication" (Luhmann 1995, p. 76). It refers us to the question of what can be addressed in a specific strategy or innovation process. Hence, openness of a strategy or innovation process with regards to the fact dimension concerns the range of different topics that can be discussed. In a traditional or "closed" product innovation process, for example, communication might be restricted to a specific, pre-defined product group or market (e.g. Bower and Christensen 1996). Open innovation processes, on the other hand, will typically be much more receptive to ideas about innovation in a wide variety of different product groups or markets (e. g., Baldwin and von Hippel 2011).

The last dimension of meaning, temporality, concerns the temporal projections in communication, particularly the past events and experiences on which communication is based as well as the future aims and goals at which communication is directed (Elias 1992; Luhmann 1995, 2013). Hence, openness of a communication process with regards to the time dimension refers us to openness in terms of the capability to integrate different purposes by allowing for different interpretations of the past, as well as different visions for the future (Kaplan and Orlikowski 2013). A "closed" strategy process, for example, will be characterized by a very restrictive 
understanding of the lessons to be learnt from the company's past, as well as a rather limited range of options that are deemed as desirable for the company's future. As a result, the range of meaningful purposes of that strategy process, i. e. acceptable strategies, will be very limited as well (cf. Hendry and Seidl 2003). An open strategy process, on the other hand, puts both, the lessons to be learnt from the company's past, as well as the visions for its future, up for discussion. As a result, the number of acceptable and meaningful purposes that might drive the whole strategy process in the end will rise (cf. MacIntosh and MacLean 1999).

Apart from offering a refined understanding of the constitutive dimensions of meaning in communication, Luhmann's communication theory points us to some important tensions that exist between these dimensions. As the capacity of organizations to deal with complexity is limited, increasing the openness, and hence complexity, of a communication process in one dimension of meaning will result in pressures to provide structure, that is, to decrease openness, with regards to another dimension of meaning (Luhmann 1995, 2012). If an organization, for example, decides to let multiple stakeholder groups participate in its strategy process, thereby increasing the openness with regards to the social dimension of meaning, the overall complexity of this process will rise. One way to reduce this complexity again could be to somehow restrict the discussions among these stakeholder groups to a limited number of topics or even to a single topic. Examples for such an approach are crowdsourcing approaches described by Afuah and Tucci (2012), which invite all kinds of participants ("distant search") to address one specific problem.

This points us to an insight that has just recently come to the attention of open strategy scholars (see Hautz et al. 2017). Openness is not something that is unconditionally desirable and productive: Openness constitutes a continuous challenge to the formation and continuation of strategy and innovation processes because there exists a "risk of dysfunctional escalation of openness, for example the excessive promotion of individual interests of problems of information overload" (Hautz et al. 2017 , p. 4). Therefore, opening up a process in an uncontrolled way and on all dimensions can also introduce a level of internal complexity that results in chaos and the dissolution of this process (as a meaningful unity). Only, if the openness of the process is at, rather than over, the edge of chaos, will we see the emergence and adaptivity that enables organizations to acknowledge the inherently emergent character of strategy-making (Mintzberg and Waters 1985; Schmitt 2010) as well as the exaptive potential of innovations (Dew et al. 2004).

On the basis of these conceptual considerations, we can develop a basic framework of openness from a communication perspective, which is represented in Fig. 1. In this figure the three dimensions of openness are represented as corners of a triangle. The higher the degree of openness in a particular dimension, the further the respective corner is pushed outwards. The surface area of the triangle symbolizes the overall complexity of the communication process, which is a result of the degrees of openness in the three dimensions: The higher the degree of openness, the larger the surface area. Hence, when extending the degree of openness in one dimension one has to reduce the degree of openness in the other dimensions if one wants to keep the overall surface area, i.e. overall complexity, at the same level. However, the figure also symbolizes that the extension of openness in one dimension typically 


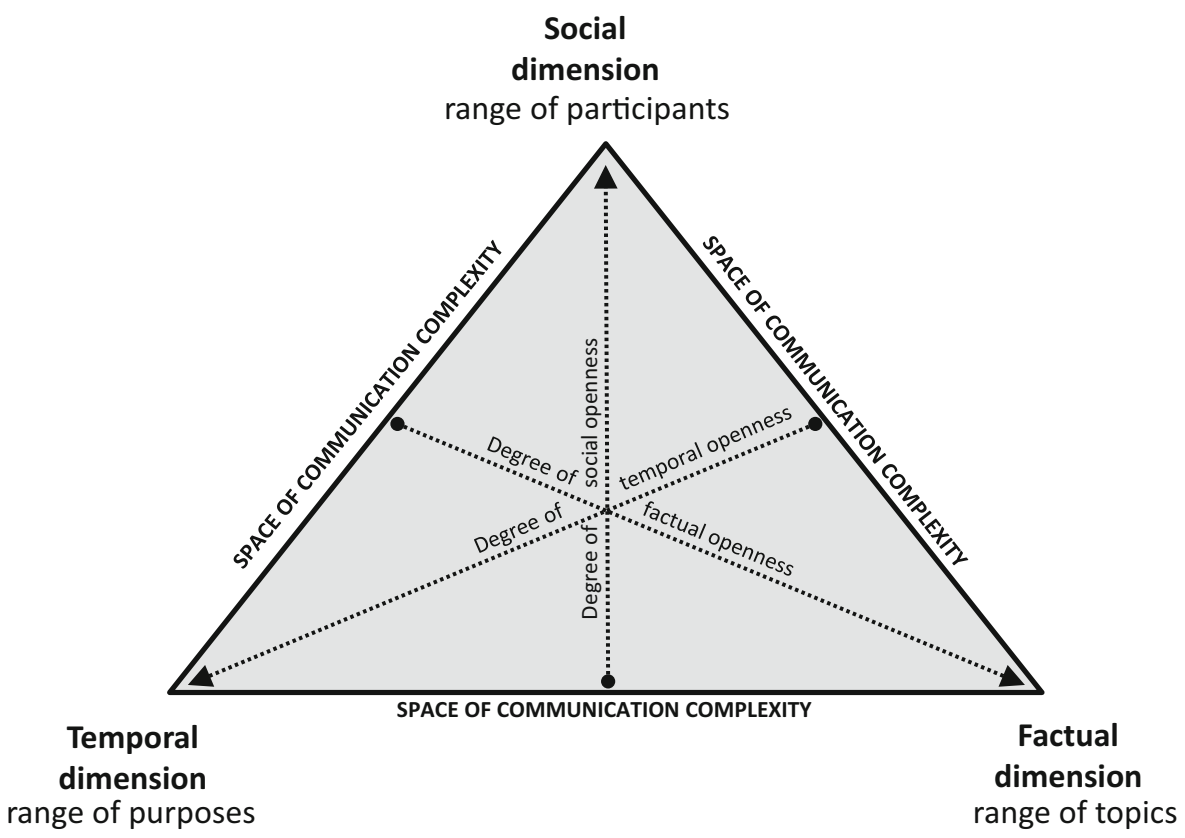

Fig. 1 Communicative Complexity Resulting from Different Degrees of Openness

also affects the degree of openness in the other dimensions, i. e. by pushing out one corner of the triangle, the other arrows become longer as well - unless those angles are pushed in. For example, by extending the range of people involved in the strategy or innovation processes we would typically expect that more topics will be brought up and a greater variety of purposes will be brought in by those participants - unless the topics and purposes are actively restricted.

Taken together, this framework of openness enables us to develop an answer to our basic research question, namely in how far communication processes in open strategy and open innovation differ. On this basis we can now analyze the respective literatures with regard to the differences and commonalities in the three dimensions of openness - factuality, sociality and temporality - and with regard to how openness in each of these dimensions is established and sustained effectively.

\section{Similarities and differences between open innovation and open strategy}

The literature on open strategy tends to emphasize the commonalities it shares with open innovation. This is not surprising given that open strategy and open innovation are often portrayed as overlapping concepts and open strategy as a variant of open innovation (Chesbrough and Appleyard 2007) or vice versa (Whittington et al. 2011). Notwithstanding the commonalities we identified on a more general level, a closer analysis of the empirical cases of open strategy and open innovation 
also reveals some significant differences. In the following, we present the results of our analysis of similarities and differences between the domains of open strategy and open innovation. In order to do so, we reviewed the empirical literature on open innovation and open strategy. While the former literature is massive (Dahlander and Gann 2010), the latter is still comparatively small. To date, there are twenty empirical studies on open strategy, some of which are still part of the "grey literature", i.e. working papers or conference papers (see Table 1 for an overview of all existing empirical studies). Given the novelty of the phenomenon of open strategy and the comparatively small number of empirical papers, we have examined each of the twenty papers very closely, while we relied partly on existing reviews (Dahlander and Gann 2010; Huizingh 2011; Lichtenthaler 2011; West and Bogers 2014) in our examination of the vast literature on open innovation. We analyzed the two literatures on the basis of our framework, examining the openness of open innovation and open strategy in terms of sociality, factuality and temporality as well as with respect to the question of how this openness is accomplished effectively.

\subsection{The social dimension of openness in innovation and strategy processes}

The social dimension of openness in innovation and strategy processes refers us to the groups that are treated as relevant participants to the communication process. Looking at the studies on open innovation, it is apparent that open innovation is almost always about opening up to external actors. For example, firms may share information with members of external innovation communities (Fichter 2009), acquire technology from other companies (Fey and Birkinshaw 2005; Laursen and Salter 2006) or reveal the source code of their own products to external audiences (Henkel 2006; Henkel et al. 2014). Open innovation may even include discussing internal problems with an external audience while excluding select organizational members from participating, in order to avoid the phenomenon of "groupthink" (Bonabeau 2009; Surowiecki 2004).

With respect to the means of accomplishing and sustaining this kind of openness in innovation processes, the respective literature reports on two general types of tools. First, several studies report on the use of tools that strive to establish a collaborative climate among participants in order to develop innovations (see Fichter 2009; Rohrbeck et al. 2009). The second type of tools reported on in the analyzed literature takes a much more competitive approach. There, the innovation process is opened up to external groups by means of some sort of innovation contest that follows a winner-takes-all-logic (see Füller et al. 2011; Piller and Walcher 2006). Afuah and Tucci (2012) termed the first form "collaboration-based crowdsourcing" and the second form "tournament-based crowdsourcing".

For open strategy processes we find that, in contrast to open innovation, these processes are much more often about opening up to internal groups. Stieger et al., for example, emphasized that involving many employees in the strategy process is "a means [of creating] shared understanding, stronger commitment, and effective implementation" (Stieger et al. 2012, p. 46). The authors pointed out the role of two-way communication between management and employees: "the combination of listening and talking should lead to a dialogue, which creates new knowledge 
Table 1 Overview of Empirical Studies on Open Strategy

Open Strategy $\quad$ Empircal Case(s)
Study

Aten and Thomas

(2016)

Baptista et al.

De Gooyert et al. (2014)

Dobusch and Müller-Seitz (2012)

Gegenhuber and

Dobusch (2017)

Hardy et al. (2006)

Heracleous et al. (2017)

Hutter et al. (2017)

Luedicke et al. (2017)

Mack and Szulanski (2017)

Malhotra et al. (2017)

Neely and Leonardi (2017)

Schmitt (2010)

Stieger et al. (2012)

Teulier and Rouleau (2014)

Turco (2016)

Werle and Seidl

(2012)

Werle and Seidl

(2015)

Wolf et al. (2014)

Yakis-Douglas et al. (2017)
U.S. Navy organization using crowdsourcing technology for strategy generation processes

Social media managers responsible for social media driven open initiatives, drawn from seven organizations spanning different sectors

Single organization explored trends and developments together with internal and external stakeholders

Development of five-year strategic plan at Wikimedia (same case, different data as Heracleous et al. (2017))

Two start-up companies "buffer" and "mite" that used blogs as part of strategymaking

Multi-sector collaboration (pharmaceutical companies and community organizations) to address specific meta-problem

Development of five-year strategic plan at Wikimedia (same case but partly different data as in Dobusch and Müller-Seitz (2012))

A company-wide online platform set up by Siemens that sought strategies for creating and validating new sustainable business opportunities

The German-based Premium Cola collective invites all stakeholders to set strategy agendas and makes the entirety of its discussions, decisions, and principles available online to the interested public

Strategizing initiatives of two large companies (HealthCo and FoodCo) with different levels of centralization

Action research in the course of implementing an online crowdsourcing platform at Landcare Research for open strategy formulation

Longitudinal and comparative analysis of social media usage at two large firms with respect to enacting knowledge strategy

Open approach to building stakeholder relationships in the face of wicked issue at Shell

Internal crowdsourcing project in medium-sized technology company including four subsidiaries

Middle-manager sensemaking in inter-organizational group on introducing new software platform and to examine organizational challenges and business benefits

Radical open management and strategy-making practices based upon social media tools and offline meetings at TechCo (pseudonym)

Joint exploration of a strategic topic by several companies from different industries

Joint exploration of a strategic topic by company and supplier together with other companies from different industries

Inclusion of middle managers in strategy making in single organization

Organizations voluntarily shared information in 554 M\&A deals, thus increasing transparency 
and [allows] shared understanding to emerge in the organization" (Stieger et al. 2012, p. 60). Also in the cases investigated by Baptista et al. (2017), Luedicke et al. (2017) and Mack and Szulanski (2017) the main target groups for open strategy processes are members of the organization. Only rarely are large groups of external actors invited to participate in open strategy-making, as was the case of Wikimedia (Dobusch and Müller-Seitz 2012; Heracleous et al. 2017), where a non-profit organization invited not only its large community of volunteers but also the wider public to contribute to a one-year strategy-making process (for another such study see Malhotra et al. 2017).

Reflecting the different challenges of opening up to (mostly) external groups in open innovation, the tools used in open strategy to accomplish and sustain the openness to internal groups put much more emphasis on joint sensemaking. Hence, only tools that help in establishing collaborative forms of engagement are used. An example is the "strategy dialogue" reported on in the study of Stieger et al. which is aimed at creating "identification and understanding" (Stieger et al. 2012, p. 46) between the participants. In a similar vein, the study by Dobusch and Müller-Seitz highlights the "collaborative exchange" that is part of "collaborative strategizing where both parties interact" (Dobusch and Müller-Seitz 2012, p. 5). Especially the studies on open strategy that focus solely on joint sensemaking, such as the works by Baptista et al. (2017), De Gooyert et al. (2014), Hardy et al. (2006), Werle and Seidl $(2012$, 2015) as well as, Schmitt (2010), have shown that open strategy is performed by those who participate in meetings and workshop processes.

Taken together, we find that the means and ends of establishing and maintaining openness in the social dimension differ clearly between open strategy and open innovation. While open innovation typically strives to open up to external audiences by means of either collaboration or competition-based tools, open strategy more often strives to open up to internal audiences and stakeholders by means of tools that focus on collaborative forms of engagement.

\subsection{The fact dimension of openness in innovation and strategy processes}

The fact dimension of openness refers us to the range of topics allowing for followup communication within the respective innovation or strategy process. In the case of open innovation, openness is mostly about technological and product-related knowledge. Chesbrough (2006) has pointed out that many existing works, including those by Nelson and Winter (1982), Cohen and Levinthal (1990) and Rosenberg (1994), have already emphasized the importance of external sources of useful knowledge for internal R\&D (see also Trott and Hartmann 2009). Especially for open innovation, factual openness to other innovation processes also plays an important role. With regards to knowledge-sharing, open innovation implies that what was previously considered a "knowledge spillover" in fact concerns "purposive outbound flows of knowledge and technology" (Chesbrough 2006, p. 11).

A focal topic in the literature on open innovation are the means to establish and sustain this factual openness throughout the process. The exemplary studies included in our analysis show that organizations strive to increase the receptiveness and connectivity of their innovation processes to a wide range of topics via such measures 
as partnering and contracting (Chesbrough and Crowther 2006; Christensen et al. 2005; Fey and Birkinshaw 2005; Laursen and Salter 2006), sharing the source code of the programs they develop (Henkel 2006; Henkel et al. 2014; West 2003), collaborating informally with innovation communities (Fichter 2009), discussing strategic innovations in workshops that involve several companies and industries (Rohrbeck et al. 2009), collecting ideas via online crowdsourcing platforms (Füller et al. 2013; Piller and Walcher 2006), engaging in the commercialization of external technology by out-licensing agreements, striking alliances, generating spin-offs and promoting sales in the area of technology (Lichtenthaler and Ernst 2007).

Of specific importance for the effective accomplishment of factual openness in innovation processes is the management of intellectual property rights. The means discussed in the literature include specific licensing practices (Chesbrough 2006; Dahlander and Gann 2010), "free revealing" (Henkel et al. 2014; von Hippel and von Krogh 2003), alternative licensing, licensing open-source software or explicitly avoiding patentability (Baldwin and von Hippel 2011; Merges 2004). They all rely on the formalized appropriation of communicated content.

Of similar importance to open innovation are tools to crowdsource solutions to a problem. "Broadcast search", for example is a type of crowdsourcing that involves broadcasting to a wide audience a problem and the requirements that an appropriate solution must fulfil, in the hope that some member of that audience will provide a solution (Jeppeson and Lakhani 2010). A related tool involves sourcing ideas through contests (Afuah and Tucci 2012). The degree of openness on the fact dimension that can be accomplished by such online-tools will of course largely depend on the features of the specific online platform that is used, such as access to intermediate results, discussion boards or evaluation systems. In addition to online communication tools, the literature also points to a range of offline practices such as "innovation jams" (Bjelland and Wood 2008).

In the case of open strategy, the range of "connective" topics is not limited to defined and relatively unequivocal knowledge regarding technologies and products. Instead, and in contrast to most open innovation processes, it also includes opinions, ideas and interpretations on a wide variety of social issues. This reflects the fact that the primary focus of open strategy is joint sensemaking. Those who participate in open strategy may provide primary ideas and interpretations as well as opinions on or interpretations of what others think, say and do (Hutter et al. 2017; Luedicke et al. 2017; Mack and Szulanski 2017; Malhotra et al. 2017; Turco 2016). For example, in their study on strategy crowdsourcing, Stieger et al. emphasized the "diversity of opinions" (Stieger et al. 2012, p. 51) that were exchanged in this way. In yet another example, Teulier and Rouleau noted that the process of participating in open strategy revealed how "the interpretations [...] differed" (Teulier and Rouleau 2014, p. 323) and how the process of participation as such helped "alleviate the divergent interpretations" (Teulier and Rouleau 2014, p. 323). Others point to the relevance of position-specific perspectives on strategic problems (Baptista et al. 2017) or the greater variety of ideas more generally (Malhotra et al. 2017; Turco 2016).

Regardless of the increased openness that open strategy processes exhibit on the fact dimension of meaning, the tools used in the effective accomplishment of that openness seem to be quite similar to those used in open innovation processes. 
Stieger et al. (2012), for example, described how the company they studied used web-based crowdsourcing tools for the purpose of open strategizing, which were similar to the crowdsourcing tools used in open innovation (see also Hutter et al. 2017). In the context of open strategy, tools such as strategy platforms (Stieger et al. 2012), wikis (Dobusch and Müller-Seitz 2012; Heracleous et al. 2017), blogs (Gegenhuber and Dobusch 2017), social media (Neely and Leonardi 2017) or online games (Aten and Thomas 2016) are used to crowdsource strategic suggestions. Just like in open innovation processes, we also find studies on the use of offline tools such as meetings and workshops (see, for instance, Turco 2016). In contrast to open innovation, however, the offline tools are typically conceived of as an indispensable element of - and not just as a possible supplement to - open strategy processes (e. g. Stieger et al. 2012; Dobusch and Müller-Seitz 2012).

Taken together, we find some indication that compared to open strategy processes, open innovation processes in general seem to be less open with regards to the fact dimension of meaning. More specifically, most open innovation processes will be connective only to rather unambiguous topics such as defined knowledge regarding technologies and products. Open strategy processes on the other hand, will also be open to much more polysemous topics, that is, topics which can be interpreted very differently. The means to effectively accomplish this kind of openness reflect this difference insofar as open innovation often focusses on the use of online-tools, while studies on open strategy processes highlight that offline-tools involving faceto-face interaction will be an indispensable element in most open strategy processes. In turn, unrestricted use of online tools may lead to substantial distractions, as was documented by the analysis of social media use by Neely and Leonardi (2017), who found that non-work related content shared via these tools can become a source of tension for enacting strategy.

\subsection{The temporal dimension of openness in innovation and strategy processes}

The temporal dimension of openness in innovation and strategy processes refers us to openness with regards to the variety of interpretations of the past (e.g., founding myths and historical backgrounds of current strategies) and the future (e. g., strategic plans and visions), and, hence, point us to the different purposes that are typically accepted as a basis for communication. Studies on open innovation have revealed three main purposes of such processes: First, many studies refer to advantages in R\&D as a reason for opening up. For example, Laursen and Salter (2006) argued that openness is a way "to draw in ideas from outsiders to deepen the pool of technological opportunities". Second, many organizations highlight standardization and ecosystem development (separately or in addition to the benefits gained in the domain of $\mathrm{R} \& \mathrm{D}$ ) as reasons for opening up. In particular, they point to the marketing benefits that can be generated by increasing "the extent and pace of diffusion of that innovation relative to what it would be if the innovation were either licensed at a fee or held secret" (von Hippel and von Krogh 2003, p. 301). Studies on open-source software in particular emphasize that openness ensures that a product remains "compatible to other products" (Henkel 2006, p. 961) and helps products succeed in "standard contests" (West 2003, p. 1279). Third, some studies refer to 
impression management in this regard. For example, according to Henkel (2006, p. 961), wanting to "appear as a good player in the open source community" is one of the most important motives for revealing software code (aside from the legal requirements that are associated with open source licenses).

To sum up, it can be said that the rather clear-cut focus of open innovation on products and related engineering problems tends to be associated with moderate levels of openness in the temporal dimension of meaning. In line with this insight, studies on open innovation do not report on specific tools that would enable an organization to deal with radically new visions of the company's future or help in integrating competences that differ substantially from the established set of competencies and values acquired through past experiences.

In contrast to open innovation, open strategy processes are often confronted with "wicked issues" that call for "less controlled, open and sense-making oriented strategizing with stakeholders" (Schmitt 2010, p. 11). Apart from one (Yakis-Douglas et al. 2017), all twenty empirical studies on open strategy emphasize the central role of joint sensemaking, where strategy-related communication allows for the emergence of a wider scope or a greater depth of issues being addressed in strategymaking. Schmitt (2010), for example, described a process of collaborative strategymaking at a multinational company posited that its purpose is to create and co-construct "shared understanding" (Schmitt 2010, p. 14) among stakeholders in the face of radically new challenges. Another example are the studies by Werle and Seidl $(2012,2015)$ which described two cases in which groups of organizations engaged in the joint exploration of strategic topics that they had not been able to make sense of on their own. Baptista and colleagues (2017), in turn, even introduce the capability of "reflexiveness" in sensemaking as both precondition for and outcome of greater openness in strategy-making. Finally, in a case of "radical openness" analyzed by Luedicke et al. (2017, p. 12), open strategizing resulted "in a continuous rejuvenation of a collective identity" while, at the same time, endowing "the organization with a particularly strong sense of moral purpose."

Given the central importance of openness to a wide variety of purposes in strategy processes, the studies on open strategy also report on a number of approaches to accomplish this kind of openness. The reported tools almost always focus on some form of intensive real-time interactions within well-defined groups (Turco 2016). Werle and Seidl (2012, 2015), for example, show how the exchange between participants of different organizations gave rise to new understandings of strategic issues that none of the participants would have been able to develop on their own. Similarly, Hardy et al. analyzed collaborative strategy-making that concerned metaproblems and showed that such practices helped construct "shared meanings and understandings" (Hardy et al. 2006, p. 108). In the case of radically open strategizing investigated by Luedicke et al. (2017), the organization relied on intensive mailing-list discussions and occasional Skype conferences. De Gooyert et al. (2014) described how an individual organization involved its internal and external stakeholders in the joint exploration of strategic developments and trends. Wolf et al. (2014) and Teulier and Rouleau (2014) also examined open strategy-making, focusing on sensemaking within different group-formations. Aten and Thomas (2016, p. 6), in turn, present the case of a "highly bureaucratized organization" - the U.S. Navy 
-, where officials turned to crowdsourcing technology in an attempt "to find new and innovative strategies"; the format of the strategizing initiative was a specifically designed online gaming environment, which provided participants with strategically relevant information on "everything from marketing to training and preparation, to subject matter analyzing, to security and $\mathrm{PAO}$, and contracts, and union legalities and negotiations" (Aten and Thomas 2016, p. 14).

Taken together, we find that there are marked differences between open innovation and open strategy processes with respect to their openness on the temporal dimension of meaning. Open innovation processes do generally not require the participating actors to integrate radically new visions and values and be open to radically new competence-sets. The opposite seems to be true for open strategy processes which, in most cases, are opened up in order to deal with radically new developments in the organizations' internal and external environment. Consequently, effective open strategy processes make use of communication tools that enable the participants mostly via some form of real-time interaction within a well-defined group - to make sense of uncertain developments and emergent trends.

\section{Discussion}

Comparing the empirical literature on open strategy to exemplary open innovation studies has revealed similarities but also important differences between the two phenomena. In this section we mainly focus on the differences between the two concepts in the context of our communication-theoretical framework. Table 2 provides an overview of the key differences between open strategy and open innovation along the three analytical dimensions of sociality, factuality and temporality.

When looking at the differences between open innovation and open strategy along Luhmann's $(1995,2012,2013)$ three dimensions of meaning, we can observe differences with regard to the degree of the respective openness. Open innovation is generally very open on the social dimension, inviting very wide and diverse "crowds" of people to contribute, for example, in "distant search" (Afuah and Tucci 2012). Leveraged by mainly digital crowdsourcing tools, the openness in terms of participants typically comes at the cost of restricting openness regarding topics and/or purposes in the factuality and temporality dimensions respectively.

Contrariwise, the empirical open strategy studies analyzed in this paper show a greater bandwidth of topics and purposes being discussed with comparably less openness in terms of potential contributors. Often, cases of open strategy-making only invite members of the respective organization to contribute. Our communication lens on the two phenomena thus reveals not only in what way open innovation and open strategy differ, but also show that neither of the two may feature completely unrestricted openness. In Fig. 2, we have illustrated the characteristic differences between open innovation and open strategy in terms of their degrees of openness in the three dimensions of meaning. Open innovation tends to have a very pointed shape with a long arrow in the social dimension, but short arrows in the other two dimensions. Open strategy in contrast has a fairly flat shape, with a short arrow in 
Table 2 Differences between open strategy and open innovation in terms of factuality, sociality and temporality

Open Strategy Open Innovation

Sociality

Openness as increasing the number of people who are addressed and/or listened to (Who is treated as relevant?)

- Opening up to internal groups \& stakeholders

- Opening up to external actors \& audiences

- Collaboration-based crowdsourcing

- Two-way communication

- Collaboration-based tools for joint sense-

- Tournament-based crowdsourcing (innovation contests) making

$\rightarrow$ Opening up to internal audiences by means of collaborative forms of engagement

$\rightarrow$ Opening up to external audiences by means of collaboration or competition-based tools

Factuality

Openness as increasing the number of different topics that can be discussed (What can be addressed?)

- Differing opinions (of what others think, say, do), ideas, interpretations

- Technological knowledge

- Position-specific perspectives on strategic problems

- Product information

- Increase receptiveness of innovation process to wide range of topics (e.g. via partnering, contracting, sharing source code etc.)

- Offline tools (e. g. meetings, workshops) as indispensable element

- Managing of intellectual property (licensing)

- Offline tools (e. g. meetings, workshops) as possible supplement

$\rightarrow$ Open to much more polysemous topics and greater importance of face-to-face communication

$\rightarrow$ Less open with regards to fact dimension of meaning; most open to rather unambiguous topics; focus on online tools

Temporality

Openness as increasing the number/variety of different interpretations of the past/visions of the future (Which purposes can be integrated?)

- Developing shared understanding through joint exploration and sensemaking for greater scope or depth of issues

- Co-creation for new understanding (beyond individual participants' scope)

- Complex meta-problems

- Commitment and ownership

$\rightarrow$ High levels of openness in order to deal with radically new developments (focus on organizations' internal and external environment)
- Obtaining technological benefits (R\&D)

- Obtaining marketing benefits (standardization \& ecosystem development)

$\rightarrow$ Moderate levels of openness with regards to temporal dimension of meaning (due to focus on products \& engineering problems)

the social dimension, but long arrows in the other two dimensions. In spite of these differences, the surface area of the two triangles is more or less the same.

However, while drawing these broad distinctions between open innovation and open strategy seems to be a permissible generalization, we can also observe a lot of variation within these groups. Some open strategy processes are indeed more open with regard to the social dimension, for instance in the case of Wikimedia, where literally thousands of volunteers and Wikipedia readers were invited to take part in a one year strategy process. As described by Dobusch and Müller-Seitz (2012), this openness created substantial difficulties to bring the open strategymaking process to a close, ending in a tiny group of consultants finalizing the 
Fig. 2 Differences in the Typical "Shapes" of Openness

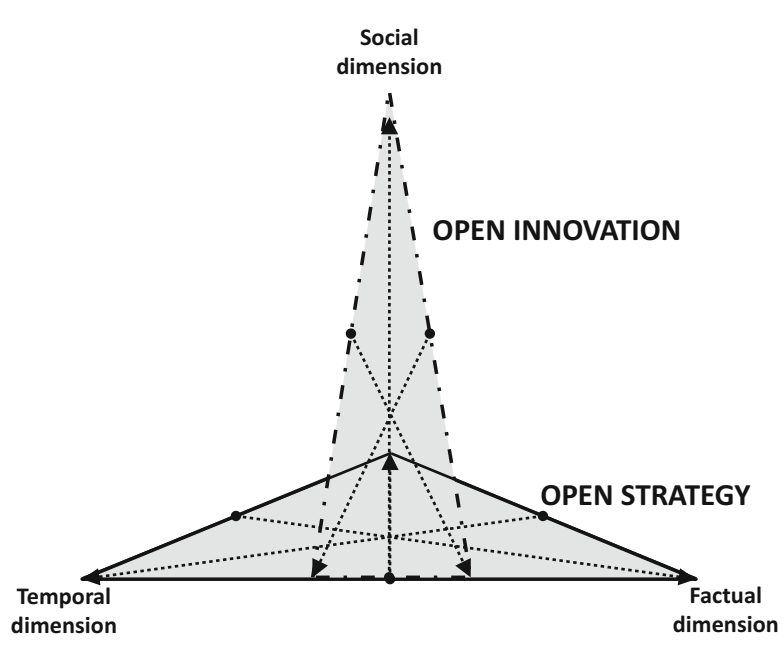

strategic proposals eventually (see also Heracleous et al. 2017). On a much more general level, this is also discussed by Hautz et al. (2017), who speak about dilemmas of open strategy. Dilemmas of process, commitment, empowerment, disclosure, and escalation, all refer to the pressures on the fact and/or the time dimension that come from opening up the social dimension and which are likely to only unfold over time. The flipside is also true for some cases of open innovation that are more open in the temporal dimension (e.g., Fichter 2009) effectively resulting in restrictions on who was allowed to participate in the social dimension of increasingly "strategic" innovation decisions.

In our analysis of open innovation and open strategy so far, we have dealt with each separately. Yet, the processes of innovation and of strategy-making are often interlinked. For instance, comprehensive concepts of open innovation as a paradigm (see, e.g. Chesbrough 2006; von Hippel 2005) and works that place open innovation in the tradition of absorptive capacity (see, e. g. West and Gallagher 2006) increasingly incorporate aspects of open strategy. In some cases, topics that concern innovation are addressed from a perspective that is informed by strategy-making; in other cases, innovation and strategy are treated as alternating phases. As mentioned above, Whittington et al. (2011) would even go so far as to treat innovation as part of strategy. "Fundamentally," they argue, "open innovation is a subset of open strategy: innovation is just one of many kinds of strategy process increasingly subject to openness" (Whittington et al. 2011, p. 543); for them, innovation is always strategic. While we agree that innovation and strategy are often closely related, we do not subscribe to this line of reasoning. Rather, we would argue that, even where strategy and innovation are linked empirically, it is possible to distinguish between them analytically. Thus, in contrast to Whittington and his colleagues, we distinguish between cases of open innovation that do not involve open strategy and cases that combine both.

A good example of cases that combine open innovation and open strategy is user innovation, where focal organizations pick up and build upon innovations that have 
emerged in a user community (Füller et al. 2013; Piller and Walcher 2006; von Hippel 2005). If open innovation becomes part of the strategy process, joint sensemaking will become important. For example, Fichter (2009) discussed organizations that share organizational and informational resources and thus build an innovation community, which contributes ideas and solutions that the organizations pick up and develop further. However, the necessity to build a community with certain rules and boundaries as a basis for joint sensemaking effectively reduces openness compared to mere crowdsourcing approaches. In other words, an organization is likely to pay a price in terms of openness in the sociality dimension due to adding the variety of accepted purposes by including strategic aspects and thus effectively increasing openness in the temporal dimension.

This has implications for those cases where open innovation may lead organizations to open up in other aspects of the value-creation process, such as strategy. Henkel et al. (2014, p. 888), for instance, speculated that open innovation "might be a potential first step toward more intensive collaborations with externals". However, in the light of our comparison between open innovation and open strategy, we would expect such a development to require some re-balancing regarding openness in the sociality dimension. In other words, organizations probably need to be more careful in selecting potential participants for overall strategy-making than for those contributing innovative ideas.

\section{Conclusion and avenues for future research}

In this paper, we have developed a communication-theoretical perspective on open strategy and open innovation. We argued that in its most general sense openness in strategy and innovation concerns aspects of communication. Drawing on Luhmann's (1995) communication theory, we identified three different dimensions of communicative openness - openness in terms of the range of people participating in the communication (social dimension), openness in terms of the range of topics (factual dimension) and openness in terms of the range of purposes of communication (temporal dimension). The greater the degree of communication in these dimensions, the greater is the complexity of the communication process. We argued that due to the limited capacity to handle communicative complexity, there are limits to the degree of openness. Hence, increasing openness in one dimension is typically associated with lowered degrees of openness in others. Reviewing the respective empirical literature, we identified similarities and differences of openness in the three dimensions between open strategy and open innovation. On the most abstract level, we find that cases of open innovation tend to exhibit high degrees of openness in the social dimension and lower degrees of openness in the other two, while open strategy tends to exhibit the opposite constellation with lower degrees of openness in the social dimension and higher degrees in the other two.

Against the background of our communication-theoretical framework and the reviewed literature we can now develop an agenda for future research on openness in strategy and innovation. We propose three main areas for future studies. The first area of research concerns the different constellations of openness regarding the 
different dimensions. While we have already identified general differences between open strategy and open innovation in their tendencies to open up in the different dimensions, we lack systematic research into the specific ways in which the three dimensions interrelate. As addressed above, changes in the degree of openness in one dimension typically lead to changes also in the other dimensions - unless the latter changes are actively restricted. For example, including more people will typically lead to a greater variety of topics and purposes that these additional people bring in, if this is not actively restricted. Future research should examine systematically the mechanisms through which the different dimensions of openness are related to each other and the techniques through which natural increases in openness can be restricted. Such research could also result in a typology of constellations of openness in the areas of strategy and innovation. At the same time, various topics in either strategy or innovation may have an impact on how respective processes unfold, making it worthwhile to bring the actual issues discussed back in.

The second area of research concerns the developmental dynamics of openness. As existing research has shown, the degree of openness often changes in the course of a strategy or innovation process. Dobusch and Müller-Seitz (2012), for example, described how the strategy process at Wikimedia changed between phases of extreme openness and closure. Such changes in openness over time can be seen as ways of managing the communicative complexity resulting from openness. As studies have shown (Hautz et al. 2017; Baptista et al. 2017), reducing degrees of openness tends to lead to tensions that need to be managed skillfully. Future research could track systematically how openness and closure of strategy and innovation processes change over time trying to identify characteristic patterns - particularly also across the three different dimensions of openness. Furthermore, future studies could examine how such changes in openness are accomplished - and challenged - by either focal or more decentralized actors.

The third area of research concerns the role of technologies in managing openness. As the literature has shown (Whittington et al. 2011; Haefliger et al. 2008), the emergence of new technologies has enabled the trend toward more openness in strategy and innovation. Apart from making possible to reach more distant audiences, these new technologies are offering new means of handling communicative complexity. For example, crowdsourcing software (Aten and Thomas 2016; Stieger et al. 2012) allows structuring and processing thousands of contributions. From the perspective of our communication theoretical model, this means that the communication technology influences the degree of overall complexity that can be handled and hence the possible expansion of the surface area of our triangle of openness. Based on this line of reasoning, future research could examine the precise impact of different technologies on the ability to handle complexity in the three dimensions of openness. For example, some technologies might be better at handling complexity in the social dimension while others might be better at handling complexity in the temporal or factual dimension.

Taken together, our communication-theoretical perspective on openness in the field of strategy and innovation offers a way to compare and relate these diverse literatures in a meaningful way and highlights a range of different avenues for future research. These research opportunities have the potential not only to advance 
our theoretical understanding but also to shape the practical engagement with these important new developments in business life.

Acknowledgements Open access funding provided by University of Innsbruck and Medical University of Innsbruck.

Open Access This article is distributed under the terms of the Creative Commons Attribution 4.0 International License (http://creativecommons.org/licenses/by/4.0/), which permits unrestricted use, distribution, and reproduction in any medium, provided you give appropriate credit to the original author(s) and the source, provide a link to the Creative Commons license, and indicate if changes were made.

\section{References}

Afuah A, Tucci CL (2012) Crowdsourcing as a solution to distant search. Acad Manage Rev 37(3):355-375

Aten K, Thomas GF (2016) Crowdsourcing Strategizing: communication technology affordances and the communicative constitution of organizational strategy. Int J Bus Commun 53(2):148-180

Baptista J, Wilson AD, Galliers RD, Bynghall S (2017) Social media and the emergence of reflexiveness as a new capability for open strategy. Long Range Plann 50(3):322-336

Baldwin C, von Hippel E (2011) Modeling a paradigm shift: from producer innovation to user and open collaborative innovation. Organ Sci 22(6):1399-1417

Bjelland OM, Wood RC (2008) An inside view of IBM's "innovation jam. MIT Sloan Manage Rev 50(1):32-40

Bonabeau E (2009) Decisions 2.0: the power of collective intelligence. MIT Sloan Manage Rev $50(2): 45-52$

Bower JL, Christensen CM (1996) Disruptive technologies: catching the wave. J Prod Innov Manage 1(13):75-76

Chesbrough HW (2003a) Open innovation: the new imperative for creating and profiting from technology. Harvard Business School Press, Boston

Chesbrough HW (2003b) The era of open innovation. MIT Sloan Manage Rev 44(3):35-41

Chesbrough HW (2006) Open innovation: a new paradigm for understanding industrial innovation. In: Chesbrough HW, Vanhaverbeke W, West J (eds) Open innovation: researching a new paradigm. Oxford University Press, Oxford, pp 1-12

Chesbrough HW, Appleyard MM (2007) Open innovation and strategy. Calif Manage Rev 50(1):57-76

Chesbrough H, Crowther AK (2006) Beyond high tech: early adopters of open innovation in other industries. R D Manage 36(3):229-236

Christensen JF, Olesen MH, Kjær JS (2005) The industrial dynamics of open innovation: evidence from the transformation of consumer electronics. Res Policy 34(10):1533-1549

Cohen WM, Levinthal DA (1990) Absorptive capacity: a new perspective on learning and innovation. Adm Sci Q 35(1):128-152

Craig RT, Muller HL (eds) (2007) Theorizing communication: readings across traditions. SAGE, Thousand Oaks

Dahlander L, Gann DM (2010) How open is innovation? Res Policy 39(6):699-709

De Gooyert V, Rouwette E, Van Kranenburg H, Freeman E, Van Breen H (2014) Mental model renewal in inter-organizational strategizing: bridging the cognitive gap between internal and external stakeholders. Paper presented at Workshop on Open Strategy, Said Business School, Oxford, 01.7.2014.

Dew N, Sarasvathy SD, Venkataraman S (2004) The economic implications of exaptation. J Evol Econ 14(1):69-84

Dobusch L, Müller-Seitz G (2012) Strategy as a practice of thousands: the case of Wikimedia. Acad Manage Proc. https://doi.org/10.5465/AMBPP.2012.43

Doz YL, Kosonen M (2008) Fast strategy: how strategic agility Will help you stay ahead of the game. Pearson, Harlow

Elias N (1992) Time. An essay. Blackwell, Oxford

Fey C, Birkinshaw J (2005) External sources of knowledge, governance mode and R\&D performance. J Manage 31(4):597-621

Fichter K (2009) Innovation communities: the role of networks of promotors in Open Innovation. R D Manage 39(4):357-371 
Franzoni C, Sauermann H (2014) Crowd science: the organization of scientific research in open collaborative projects. Res Policy 43(1):1-20

Füller J, Hutter K, Faullant R (2011) Why co-creation experience matters? Creative experience and its impact on the quantity and quality of creative contributions. R D Manage 41:259-273

Füller J, Schroll R, von Hippel E (2013) User generated brands and their contribution to the diffusion of user innovations. Res Policy 42(6-7):1197-1209

Gegenhuber T, Dobusch L (2017) Making an impression through openness: how open strategy-making practices change in the evolution of new ventures. Long Range Plann 50(3):337-354

Haefliger S, Von Krogh G, Spaeth S (2008) Code reuse in open source software. Manage Sci 54(1):180-193

Hardy C, Lawrence T, Phillips N (2006) Swimming with sharks: creating strategic change through multisector collaboration. Int J Strateg Change Manage 1(1/2):96-112

Hautz J, Seidl D, Whittington R (2017) Open strategy: dimensions, dilemmas, dynamics. Long Range Plann 50(3):298-309

Hendry J, Seidl D (2003) The structure and significance of strategic episodes: social systems theory and the routine practices of strategic change. J Manage Stud 40(1):175-196

Henkel J (2006) Selective revealing in open innovation processes: the case of embedded Linux. Res Policy 35(7):953-969

Henkel J, Schöberl S, Alexy O (2014) The emergence of openness: How and why firms adopt selective revealing in open innovation. Res Policy 43(5):879-890

Heracleous L, Goesswein J, Beaudette P (2017) Open strategy-making at the Wikimedia foundation: a dialogic perspective. J Appl Behav Sci. https://doi.org/10.1177/0021886317712665

Huizingh EK (2011) Open innovation: state of the art and future perspectives. Technovation 31(1):2-9

Hutter K, Nketia BA, Füller J (2017) Falling short with participation - different effects of ideation, commenting, and evaluating behavior on open strategizing. Long Range Plann 50(3):355-370

Jeppeson LB, Lakhani KR (2010) Marginality and problem-solving effectiveness in broadcast search. Organ Sci 21(5):1016-1033

Kaplan S, Orlikowski WJ (2013) Temporal work in strategy making. Organ Sci 24(4):965-995

Laursen K, Salter AJ (2006) Open for innovation: the role of openness in explaining innovation performance among UK manufacturing firms. Strateg Manage J 27:131-150

Lichtenthaler U (2011) Open innovation: past research, current debates, and future directions. Acad Manage Perspect 25(1):75-93

Lichtenthaler U, Ernst H (2007) External technology commercialization in large firms: results of a quantitative benchmarking study. R D Manage 37(5):383-397

Luedicke MK, Husemann KC, Furnari S, Ladstaetter F (2017) Radically open strategizing: how the premium cola collective takes open strategy to the extreme. Long Range Plann 50(3):371-384

Luhmann N (1995) Social systems. Stanford University Press, Stanford

Luhmann N (2012) Translated by rhodes Barret. Theory of society, vol. 1. Stanford University Press, Stanford

Luhmann N (2013) Translated by Rhodes Barret. Theory of society, vol. 2. Stanford University Press, Stanford

MacIntosh R, MacLean D (1999) Conditioned emergence: a dissipative structures approach to transformation. Strateg Manage J 20:297-316

Mack DZ, Szulanski G (2017) Opening up: how centralization affects participation and inclusion in strategy making. Long Range Plann 50(3):385-396

Malhotra A, Majchrzak A, Niemiec RM (2017) Using public crowds for open strategy formulation: mitigating the risks of knowledge gaps. Long Range Plann 50(3):397-410

Merges RP (2004) A new dynamism in the public domain. Univ Chic Law Rev 71(1):183-203

Mintzberg H, Waters JA (1985) Of strategies, deliberate and emergent. Strateg Manage J 6(3):257-272

Neely T, Leonardi PM (2017) Enacting knowledge strategy through social media: passable trust and the paradox of non-work interactions. Strateg Manage J (in press)

Nelson R, Winter S (1982) An evolutionary theory of economic change. Belknap Press, Cambridge

Palmisano S (2004) Leading change when business is good. Interview by Paul Hemp and Thomas A. Stewart. Harv Bus Rev 82:60-70

Piller FT, Walcher D (2006) Toolkits for idea competitions: a novel method to integrate users in new product development. R D Manage 36:307-318

Putnam L, Mumby D (eds) (2013) The SAGE handbook of organizational communication. Advances in theory, research, and methods, 3rd edn. SAGE, Thousand Oaks

Rohrbeck R, Hölzle K, Gemünden HG (2009) Opening up for competitive advantage - How Deutsche Telekom creates an open innovation ecosystem. R D Manage 39(4):420-430 
Rosenberg N (1994) Exploring the black box: technology, economics, and history. Cambridge University Press, Cambridge

Schmitt R (2010) Dealing with wicked issues: open strategizing and the camisea case. J Bus Ethics 96:11-20

Stieger D, Matzler K, Chatterjee S, Ladstaetter-Fussenegger F (2012) Democratizing strategy: how crowdsourcing can be used for strategy dialogues. Calif Manage Rev 54(4):44-69

Surowiecki J (2004) The wisdom of crowds: why the many are smarter than the few and how collective wisdom shapes business, economies, societies and nations. Anchor Books, New York

Teulier R, Rouleau L (2014) Middle managers' Sensemaking and Interorganizational change initiation: translation spaces and editing practices. J Change Manage 13:308-337

Trott P, Hartmann D (2009) Why "open innovation" is old wine in new bottles. Int J Innov Manage 13(4):715-736

Turco C (2016) The conversational firm: rethinking bureaucracy in the age of social media. Columbia University Press, New York

von Hippel E, von Krogh G (2003) Free revealing and the private-collective model for innovation incentives. R D Manage 36(3):295-306

von Hippel E (2005) The democratization of innovation. MIT Press, Cambridge

Werle F, Seidl D (2012) Inter-organizational strategizing as extension of sensemaking capacities. Working Paper. University of Zurich, Zurich

Werle F, Seidl D (2015) The layered materiality of strategizing: epistemic objects and the interplay between material artefacts in the exploration of strategic topics. Br J Manage 1:67-89

West J (2003) How open is open enough? Melding proprietary and open source platform strategies. Res Policy 32:1259-1285

West J, Bogers M (2014) Leveraging external sources of innovation: a review of research on open innovation. J Prod Innov Manage 31(4):814-831

West J, Gallagher S (2006) Challenges of open innovation: the paradox of firm investment in open-source software. R D Manage 36(3):319-331

Whittington R, Cailluet L, Yakis-Douglas B (2011) Opening strategy: evolution of a precarious profession. Br J Manage 22(3):531-544

Wolf C, Jacobs C, Floyd S (2014) Talking or walking the talk? Middle management inclusion in strategy work. Paper presented at Workshop on Open Strategy, Said Business School, Oxford, 01.7.2014.

Yakis-Douglas B, Angwin D, Meadows M (2017) Opening M\&A strategy to investors: predictors and outcome of transparency during organizational transition. Long Range Plann 50(3):411-422 